\title{
Correction to: Efficacy of Acceptance and Commitment Therapy in Daily Life (ACT-DL) in early psychosis: study protocol for a multi-centre randomized controlled trial
}

Ulrich Reininghaus ${ }^{1,2,3^{*}}$, Annelie Klippe ${ }^{2,4 \dagger}$, Henrietta Steinhart ${ }^{2,4 \dagger}$, Thomas Vaessen ${ }^{2,4 \dagger}$, Martine van Nierop ${ }^{4}$, Wolfgang Viechtbauer ${ }^{2}$, Tim Batink$^{2}$, Zuzana Kasanova ${ }^{4}$, Evelyne van Aubel ${ }^{4}$, Ruud van Winkel ${ }^{5}$, Machteld Marcelis², Therese van Amelsvoort ${ }^{2}$, Mark van der Gaag ${ }^{6}$, Lieuwe de Haan ${ }^{7}$ and Inez Myin-Germeys ${ }^{4}$

\section{Correction to: Trials 20, 769 (2019)}

\section{https://doi.org/10.1186/s13063-019-3912-4}

Following the publication of the original article [1], the authors discovered a typographical error in the method section under the inclusion criteria subsection. The text "[the] inclusion criteria are as follows: (1) aged 16-65 years" should read "[the] inclusion criteria are as follows: (1) aged 15-65 years". The authors were granted ethical approval for this age range by the MERC at Maastricht University Medical Centre (MUMC), The Netherlands reference: (NL46439.068.13) and the University Clinical Leuven, Belgium (reference: B322201629214). The typographical error therefore has had no implications for the RCT.

\footnotetext{
Author details

'Department of Public Mental Health, Central Institute of Mental Health, Medical Faculty Mannheim, University of Heidelberg, Mannheim, Germany. ${ }^{2}$ Department of Psychiatry and Psychology, School for Mental Health and Neuroscience, Maastricht University, Maastricht, The Netherlands. ${ }^{3}$ ESRC Centre for Society and Mental Health and Centre for Epidemiology and Public Health, Health Service and Population Research Department, Institute of Psychiatry, Psychology and Neuroscience, King's College London, London,
}

UK. ${ }^{4}$ Department of Neurosciences, Psychiatry Research Group, Center for Contextual Psychiatry, KU Leuven, Leuven, Belgium. ${ }^{5}$ Universitair Psychiatrisch Centrum KU Leuven, Kortenberg, Belgium. ${ }^{6}$ Department of Clinical Psychology, VU Amsterdam, Amsterdam, The Netherlands. ${ }^{7}$ Department of Psychiatry, University of Amstderdam, Amsterdam, The Netherlands.

Published online: 16 August 2021

\section{Reference}

1. Reininghaus, et al. Efficacy of Acceptance and Commitment Therapy in Daily Life (ACT-DL) in early psychosis: study protocol for a multi-centre randomized controlled trial. Trials. 2019;20:769. https://doi.org/10.1186/s13 063-019-3912-4

* Correspondence: ulrich.reininghaus@zi-mannheim.de

${ }^{+}$Annelie Klippel, Henrietta Steinhart and Thomas Vaessen contributed equally to this work

${ }^{1}$ Department of Public Mental Health, Central Institute of Mental Health, Medical Faculty Mannheim, University of Heidelberg, Mannheim, Germany ${ }^{2}$ Department of Psychiatry and Psychology, School for Mental Health and Neuroscience, Maastricht University, Maastricht, The Netherlands Full list of author information is available at the end of the article

(c) The Author(s). 2021 Open Access This article is licensed under a Creative Commons Attribution 4.0 International License, which permits use, sharing, adaptation, distribution and reproduction in any medium or format, as long as you give appropriate credit to the original author(s) and the source, provide a link to the Creative Commons licence, and indicate if changes were made. The images or other third party material in this article are included in the article's Creative Commons licence, unless indicated otherwise in a credit line to the material. If material is not included in the article's Creative Commons licence and your intended use is not permitted by statutory regulation or exceeds the permitted use, you will need to obtain permission directly from the copyright holder. To view a copy of this licence, visit http://creativecommons.org/licenses/by/4.0/ The Creative Commons Public Domain Dedication waiver (http://creativecommons.org/publicdomain/zero/1.0/) applies to the data made available in this article, unless otherwise stated in a credit line to the data. 